independent ubiquitination of Hsp70. J Neurochem 2008;105(5):1806-1819.

7. Kim K-Y, et al. Parkin is a lipid-responsive regulator of fat uptake in mice and mutant human cells. J Clin Invest. 2011;121(9):3701-3712.

8. Chan NC, et al. Broad activation of the ubiquitin proteasome system by Parkin is critical for mitoph agy. Hum Mol Genet. 2011;20(9):1726-1737.

9. Silverstein RL, Febbraio M. CD36, a scavenger receptor involved in immunity, metabolism, angiogenesis, and behavior. Sci Signal. 2009;2(72):re3.

10. Su X, Abumrad NA. Cellular fatty acid uptake: a pathway under construction. Trends Endocrinol Metab. 2009;20(2):72-77.

11. Hajri T, Han XX, Bonen A, Abumrad NA. Defective fatty acid uptake modulates insulin responsiveness and metabolic responses to diet in CD36-null mice. J Clin Invest. 2002;109(10):1381-1389.

12. Yamashita S, et al. Physiological and pathological roles of a multi-ligand receptor CD36 in atherogenesis; insights from CD36-deficient patients. $\mathrm{Mol}$ Cell Biochem. 2007;299(1-2):19-22.

13. Love-Gregory L, et al. Common CD36 SNPs reduce protein expression and may contribute to a pro- tective atherogenic profile. Hum Mol Genet. 2011; 20(1):193-201.

14. Ghosh A, et al. Platelet CD36 surface expression levels affect functional responses to oxidized LDL and are associated with inheritance of specific genetic polymorphisms. Blood. 2011;117(23):6355-6366.

15. Lepretre F, et al. A CD36 nonsense mutation associated with insulin resistance and familial type 2 diabetes. Hum Mutat. 2004;24(1):104.

16. Bousquet M, Calon F, Cicchetti F. Impact of omega3 fatty acids in Parkinson's disease [published online ahead of print March 23, 2011]. Ageing Res Rev. doi:10.1016/j.arr.2011.03.001.

17. de Lau LM, Bornebroek M, Witteman JC, Hofman A, Koudstaal PJ, Breteler MM. Dietary fatty acids and the risk of Parkinson disease: the Rotterdam study. Neurology. 2005;64(12):2040-2045.

18. Farooqui T, Farooqui AA. Lipid-mediated oxidative stress and inflammation in the pathogenesis of Parkinson's disease. Parkinsons Dis. 2011;2011:247467.

19. Greene JC, Whitworth AJ, Kuo I, Andrews LA, Feany MB, Pallanck LJ. Mitochondrial pathology and apoptotic muscle degeneration in Drosophila Parkin mutants. Proc Natl Acad Sci U S A. 2003;
100(7):4078-4083.

20. Smith BK, et al. FAT/CD36 is located on the outer mitochondrial membrane, upstream of long-chain acyl-CoA synthetase, and regulates palmitate oxidation. Biochem J. 2011;437(1):125-134

21. Miyake Y, et al. Dietary fat intake and risk of Parkinson's disease: a case-control study in Japan. J Neurol Sci. 2010;288(1-2):117-122.

22. Farooqui AA, Horrocks LA, Farooqui T. Interactions between neural membrane glycerophospholipid and sphingolipid mediators: a recipe for neural cell survival or suicide. J Neurosci Res. 2007; 85(9):1834-1850.

23. Darios F, Ruiperez V, Lopez I, Villanueva J, Gutierrez LM, Davletov B. Alpha-synuclein sequesters arachidonic acid to modulate SNARE-mediated exocytosis. EMBO Rep. 2011;11(7):528-533.

24. Kuda O, et al. CD36 Protein Is Involved in Storeoperated Calcium Flux, Phospholipase A2 Activation, and Production of Prostaglandin E2. J Biol Chem. 2011;286(20):17785-17795.

25. Su X, Federoff HJ, Maguire-Zeiss KA. Mutant alphasynuclein overexpression mediates early proinflammatory activity. Neurotox Res. 2009;16(3):238-254.

\title{
Peripheral glucose homeostasis: does brain insulin matter?
}

\author{
Barry E. Levin ${ }^{1,2}$ and Robert S. Sherwin ${ }^{3}$
}

\begin{abstract}
${ }^{1}$ Neurology Service, Veterans Administration Medical Center, East Orange, New Jersey, USA. 2Department of Neurology and Neurosciences,
New Jersey Medical School, University of Medicine and Dentistry of New Jersey, Newark, New Jersey, USA. ${ }^{3}$ Department of Medicine,

Section of Endocrinology and Metabolism, Yale Center for Clinical Investigation, Yale University School of Medicine, New Haven, Connecticut, USA.
\end{abstract}

\begin{abstract}
Much controversy surrounds the relative role of insulin signaling in the brain in the control of hepatic glucose metabolism. In this issue of the JCI, Ramnanan and colleagues demonstrate that arterial infusion of insulin into the brains of dogs reduces net hepatic glucose output without altering endogenous glucose production. However, this effect was modest and required both prolonged fasting and prolonged exposure of the brain to insulin, raising doubts about the overall physiological relevance of insulin action in the brain on hepatic glucose metabolism. Given the dominant direct role that insulin plays in inhibiting glucose production in the liver, we suggest that the main effect of central insulin on hepatic glucose metabolism may be more chronic and assume greater significance either when portal insulin is deficient, as occurs during exogenous insulin treatment of type 1 diabetes, or when chronic hyperinsulinemia and central insulin resistance develops, as occurs in type 2 diabetes.
\end{abstract}

Insulin controls nutrient and metabolic homeostasis via effects on the liver, muscle, and adipose tissue. After a meal, insulin acts on the liver to inhibit net hepatic glucose output (NHGO) - the balance between hepatic glucose production (HGP), which occurs via gluconeogenesis and glycoge-

Conflict of interest: Robert S. Sherwin has stock options from Insulet and receives honoraria from Novartis and MannKind for service on data safety monitoring boards.

Citation for this article: J Clin Invest. 2011; 121(9):3392-3395. doi:10.1172/JCI59653. nolysis, and hepatic glucose uptake, which includes glycogen synthesis. In humans (1) and in large mammals such as the dog (2), the direct action of insulin on the liver plays a dominant role in suppressing NHGO. However, studies in rodents suggest that insulin can also act within the brain to alter hepatic glucose metabolism, primarily by suppressing HGP (Figure 1 and refs. refs. 3 , 4). In this issue of the JCI, Ramnanan and colleagues show that raising brain insulin levels in dogs using the physiologically relevant route of carotid and verte- bral arterial infusions inhibits NHGO by increasing hepatic uptake of glucose and its incorporation into glycogen (Figure 1 and ref. 5). HGP was not substantially altered, although the expression of gluconeogenic genes in liver was diminished. However, unlike the transient (approximately 1-2 hours) rise in insulin and fall in glucagon levels in the portal circulation that follows most carbohydrate-rich meals, the insulin infusions performed by Ramnanan and colleagues were carried out for 3-4 hours and the dogs were fasted for 42 hours; even under these conditions, only a relatively modest inhibition of NHGO was observed. While the work of Ramnanan and colleagues (5) confirms that insulin can act on the brain to alter hepatic glucose metabolism in dogs, it does not settle the question about the relative importance of central insulin signaling in mediating NHGO under physiological conditions in humans and other mammals.

\section{Insulin and the brain}

The brain is an insulin-sensitive organ; various studies have shown that insulin action in the brain affects energy and glu- 


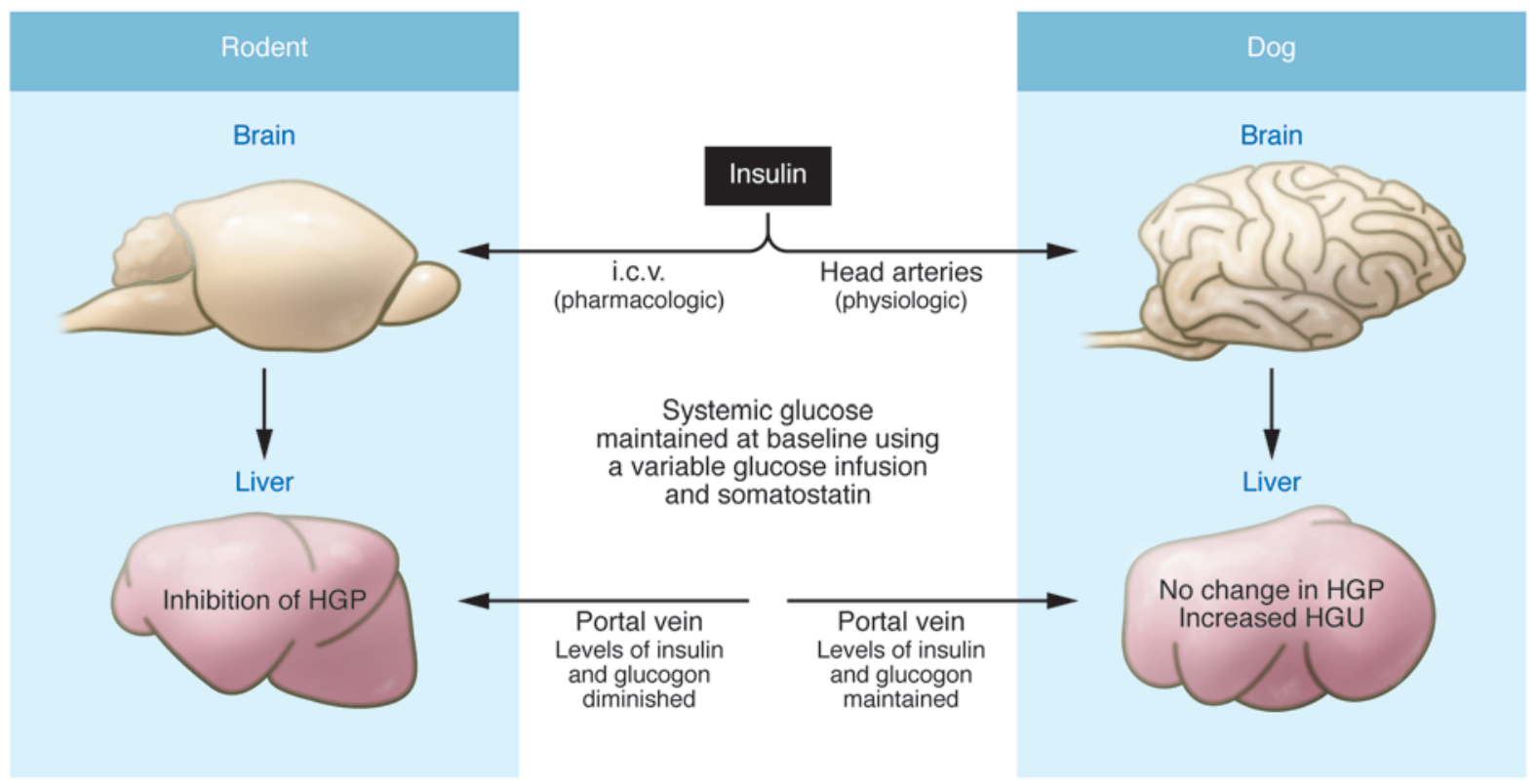

\section{Figure 1}

Effect of insulin delivery to the brain on hepatic glucose metabolism in the rat (3) and dog (5). In the rat, insulin was administered i.c.v. in supraphysiological doses, whereas in the dog, insulin was administered via direct carotid and vertebral arterial infusion, which raised levels to the upper physiological range. In both cases, plasma glucose was kept at baseline using variable glucose infusion and somatostatin to suppress endogenous insulin and glucagon secretion. However, in the rat, insulin alone was replaced systemically, whereas in the dog, both insulin and glucagon were directly delivered to the liver to maintain portal levels. In both models, changes in hepatic glucose metabolism were observed: in the rat, HGP was inhibited; in the dog, a change in HGP was not seen, but hepatic glucose uptake (HGU) increased, thereby diminishing NHGO.

cose homeostasis, neuroendocrine function, reward, memory, and learning $(3,6,7)$. Neurons in many areas of the brain express insulin receptors (InsRs), and insulin, acting on these receptors, causes activation of PI3K and MAPK signaling pathways $(8,9)$. Insulin-mediated activation of these pathways can lead to short-term changes in neuronal activity (10) or prolonged changes in gene transcription and neuronal plasticity (11), which occur within the 3- to 4-hour time frame used in the Ramnanan studies (5).

In seminal pancreatic clamp studies by Obici et al. (3), in short-term-fasted rats in which secretion of insulin and glucagon were inhibited using somatostatin and insulin was infused peripherally, i.c.v. delivery of insulin for 4-6 hours inhibited HGP by approximately $30 \%$. The central effects of insulin were thought to signal via the vagus nerve to the liver (4). However, sympathetic innervation to the liver increases hepatic gluconeogenesis and glycogenolysis (12) and might also play a role in mediating the central action of insulin (13). Thus, the collective observations in rodents suggest that insulin signaling in the brain can have an important effect on HGP. But this does not appear to be the case in dogs. Cherrington and colleagues previously found that direct delivery of insulin to the dog liver via the portal vein was the dominant inhibitor of HGP, as opposed to the effects of arterial infusions of insulin into the brain (2). In addition, any significant requirement for a central effect of insulin on neutrally mediated NHGO (4) is not supported by studies conducted in humans with denervated livers (1). Although these differences between rodents on the one hand and dogs and humans on the other might be species specific, they raise important questions regarding the role of insulin signaling in the brain in the control of HGP under short- and long-term physiologic and pathologic conditions.

\section{Are the central effects of insulin physiologically relevant?}

Many studies in rodents support a role for insulin acting on the brain as a regulator of peripheral glucose homeostasis. InsRexpressing neurons in the rat are localized in important hypothalamic and hindbrain areas that modulate glucose homeostasis, energy intake and expenditure, and neuroendocrine and autonomic functions $(8,9)$. In rodent brains, insulin has relatively acute effects on neuronal activity in vitro (14). Furthermore, in rodents, up to $75 \%$ of hypothalamic glucose-sensing neu- rons that alter their activity in response to physiological changes in ambient glucose levels also coexpress InsR and the insulindependent GLUT4 glucose transporter, thus suggesting a potential role for insulin-mediated effects on neuronal glucose uptake (15). Although such an effect has not been demonstrated directly, deletion of InsR in GLUT4-expressing neurons of mice promotes the development of diabetes (16). Moreover, administration of InsR antisense or antagonists via the third cerebral ventricle blunts the inhibitory effect of i.c.v. insulin on HGP (3). Finally, deletion of InsR signaling in agouti-related protein (AgRP) neurons in the mouse hypothalamus attenuates the central effect of insulin on HGP (17), whereas restoration of InsR in AgRP neurons in mice lacking InsR elsewhere in the brain and body restores the ability of peripheral insulin infusion to inhibit HGP (18).

On the other hand, there is strong evidence against central actions of insulin having an important role in regulating hepatic glucose metabolism under physiological conditions. First, use of somatostatin and peripheral insulin replacement alone in rodent studies decreases insulin and glucagon levels in the hepatic portal circulation, likely magnify- 
ing the effect of centrally delivered insulin on HGP (3). Second, although deletion of InsR from specific hypothalamic neurons can affect hepatic glucose metabolism, the overall effect of decreasing insulin signaling throughout the brain in mice lacking InsR in neurons is not dramatic (19), unless there is concomitant InsR deletion in peripheral insulin-sensitive tissues. Additionally, InsR deletion in the mouse germline likely alters neuronal development and plasticity. Even relatively short-term deletion of InsR from specific neurons is likely associated with changes in neuronal connectivity that could alter the neural circuits involved with glucose homeostasis (11).

There are also several technical issues that cloud interpretation of rodent and dog studies in this field. For example, studies in rats and mice generally use i.c.v. infusion of insulin at supraphysiological doses. This technique has serious shortcomings. Insulin normally enters the brain from plasma by crossing the blood-brain barrier from the arterial circulation. Insulin is also transported into cerebrospinal fluid via the choroid plexus, which contains high levels of InsR (9), from which insulin gains access to the periventricular brain areas but is unlikely to diffuse more than a short distance (20). This limits how much insulin reaches neurons involved in neuroendocrine and autonomic regulation that are distant from the ventricles. While it is often thought that insulin infused into the third cerebral ventricle primarily engages hypothalamic neurons $(3,4)$, such infusions also expose critical autonomic InsR-expressing neurons in the hindbrain nucleus tractus solitarius and dorsal motor nucleus of the vagus to high levels of insulin (8). It is also noteworthy that the euglycemic hyperinsulinemic or pancreatic clamps used to investigate the central effects of insulin signaling on hepatic glucose metabolism are carried out over long periods of time: 3-6 hours in rodents (3), and, in the case of the Ramnanan studies (5), in dogs that were fasted for 42 hours prior to the clamp. Such experimental conditions in no way mimic the relatively brief (30-180 minutes) rise and fall of circulating insulin that follows a meal or the marked suppression of HGP accompanying physiological increments in insulin, which are near maximal at 1 hour. This difference in insulin kinetics under clamp versus physiological conditions is crucial in the interpretation of the central action of insulin on HGP. In contrast, the direct effect of insulin on the liver is both rapid and dominant in the suppression of HGP (2).

\section{Making sense of the data}

To make sense of all the data, we must first ask whether existing studies carried out under a variety of experimental conditions faithfully reproduce physiological conditions. The answer to this question is likely no. Nevertheless, the studies of Ramnanan et al. suggest that, under certain conditions, insulin delivered to the brain from the systemic circulation can alter NHGO (5). However, we believe that current data continue to support the view that insulin normally regulates the liver predominantly via local delivery from the portal circulation. The close proximity of the pancreas to the liver provides high local insulin concentrations, which promote the rapid changes in NHGO observed. In contrast, passage of insulin into the brain is much slower, and its levels in the brain are much lower, than those in the general circulation (21). The contribution of CNS insulin to HGP regulation might, however, be somewhat greater in the setting of insulindeficient type 1 diabetes, where insulin is delivered systemically.

On the other hand, brain insulin signaling does appear to exert important tonic direct and/or indirect effects that serve to limit excessive HGP. Loss of insulin signaling in neurons expressing Glut4 markedly increases hyperglycemia in mice with peripheral insulin resistance (18). Furthermore, in nondiabetic rats, acute blockade of insulin signaling within the ventromedial hypothalamus, a key glucose-sensing region, immediately stimulates glucagon secretion (7). Impaired insulin secretion also appeared in preliminary studies using virus-induced knockdown of ventromedial hypothalamus InsR (R.S. Sherwin, unpublished observations). Of course, such a reduction in central insulin signaling is similar to what happens in type 2 diabetic individuals exposed to chronic hyperinsulinemia in conjunction with the development of central and peripheral insulin resistance. Thus, central insulin signaling may play its most important role in regulating hepatic glucose metabolism in such individuals when it is attenuated after prolonged hyperinsulinemia. Such a hypothesis does not require that central insulin resistance play a dominant role in the regulation of hepatic glucose metabolism. Rather, it would become an important contributor to the overall disturbance experienced by such individuals and might provide a therapeutic target for remediation of their abnormal glucose metabolism.
In conclusion, the work of Ramnanan et al. (5), together with previous studies from this group $(2,22)$, demonstrate the utility of the dog as a model in which many experimental variables can be controlled simultaneously. The current study clearly demonstrates that over time, insulin can act centrally to alter hepatic glucose metabolism under such controlled conditions. The daunting challenge going forward is to demonstrate whether such findings apply to any physiologically relevant condition or whether, as we suggest, they might be more relevant to pathological conditions such as those encountered in type 2 diabetes mellitus.

\section{Acknowledgments}

This work was supported in part by the Research Service of the Veterans Administration and NIDDK grant DK53181 to B.E. Levin, and by NIH grants DK 20495, P30 DK 45735, and UL1 RR024139 and Juvenile Diabetes Research Foundation grant 4-2004-807 to R.S. Sherwin.

Address correspondence to: Barry E. Levin, Neurology Service (127C), VA Medical Center, East Orange, New Jersey 07018, USA. Phone: 973.676.1000, ext. 1442; Fax: 973.395.7112; E-mail: levin@umdnj.edu.

1. Perseghin G, et al. Regulation of glucose homeostasis in humans with denervated livers. J Clin Invest. 1997;100(4):931-941.

2. Edgerton DS, et al. Insulin's direct effects on the liver dominate the control of hepatic glucose production. J Clin Invest. 2006;116(2):521-527.

3. Obici S, Zhang BB, Karkanias G, Rossetti L. Hypothalamic insulin signaling is required for inhibition of glucose production. Nat Med. 2002;8(12):1376-1382.

4. Pocai A, et al. Hypothalamic K(ATP) channels control hepatic glucose production. Nature. 2005; 434(7036):1026-1031.

5. Ramnanan CJ, et al. Brain insulin action augments hepatic glycogen synthesis without suppressing glucose production or gluconeogenesis in dogs. JClin Invest. 2011;121(9):3713-3723.

6. Woods SC, Lotter EC, McKay LD, Porte D Jr. Chronic intracerebroventricular infusion of insulin reduces food intake and body weight of baboons. Nature. 1979;282(5738):503-505.

7. Paranjape SA, et al. Influence of insulin in the ventromedial hypothalamus on pancreatic glucagon secretion in vivo. Diabetes. 2010;59(6):1521-1527.

8. Unger JW, Moss AM, Livingston JN. Immunohistochemical localization of insulin receptors and phosphotyrosine in the brainstem of the adult rat. NeuroScience. 1991;42(3):853-861.

9. Werther GA, et al. Localization and characterization of insulin receptors in rat brain and pituitary gland using in vitro autoradiography and computerized densitometry. Endocrinology. 1987;121(4):1562-1570.

10. Spanswick D, Smith MA, Mirshamsi S, Routh VH, Ashford ML. Insulin activates ATP-sensitive K+ channels in hypothalamic neurons of lean, but not obese rats. Nat Neurosci. 2000;3(8):757-758.

11. Levin BE, Kang L, Sanders NM, Dunn-Meynell AA. Role of neuronal glucosensing in the regulation of energy homeostasis. Diabetes. 2006; 
55(suppl 2):S122-S130.

12. Lautt WW. Autonomic neural control of liver glycogen metabolism. Med Hypotheses. 1979; 5(12):1287-1296.

13. Sakaguchi T, Bray GA. Sympathetic activity following paraventricular injections of glucose and insulin. Brain Res Bull. 1988;21(1):25-29.

14. Spanswick D, Smith MA, Mirshamsi S, Routh VH, Ashford ML. Insulin activates ATP-sensitive K+ channels in hypothalamic neurons of lean, but not obese rats. Nature Neurosci. 2000;3(8):757-758.

15. Kang L, Routh VH, Kuzhikandathil EV, Gaspers L, Levin BE. Physiological and molecular characteristics of rat hypothalamic ventromedial nucleus glu- cosensing neurons. Diabetes. 2004;53(3):549-559.

16. Lin HV, et al. Diabetes in mice with selective impairment of insulin action in glut4-expressing tissues. Diabetes. 2011;60(3):700-709.

17. Konner AC, et al. Insulin action in AgRP-expressing neurons is required for suppression of hepatic glucose production. Cell Metab. 2007;5(6):438-449.

18. Lin HV, et al. Divergent regulation of energy expenditure and hepatic glucose production by insulin receptor in agouti-related protein and POMC neurons. Diabetes. 2010;59(2):337-346.

19. Bruning JC, et al. Role of brain insulin receptor in control of body weight and reproduction. Science. 2000;289(5487):2122-2125.
20. Mullier A, Bouret SG, Prevot V, Dehouck B. Differential distribution of tight junction proteins suggests a role for tanycytes in blood-hypothalamus barrier regulation in the adult mouse brain. J Comp Neurol. 2010;518(7):943-962.

21. Gerozissis K, Rouch C, Lemierre S, Nicolaidis S, Orosco M. A potential role of central insulin in learning and memory related to feeding. Cell Mol Neurobiol. 2001;21(4):389-401.

22. Sindelar DK, Balcom JH, Chu CA, Neal DW, Cherrington $\mathrm{AD}$. A comparison of the effects of selective increases in peripheral or portal insulin on hepatic glucose production in the conscious dog. Diabetes. 1996;45(11):1594-1604.

\title{
Finally! A human pancreatic $\beta$ cell line
}

\author{
Gordon C. Weir and Susan Bonner-Weir
}

Section on Islet Cell Biology and Regenerative Medicine, Research Division, Joslin Diabetes Center, and Department of Medicine, Harvard Medical School, Boston, Massachusetts, USA.

\begin{abstract}
For decades, investigators have made numerous attempts to generate human pancreatic $\beta$ cell lines that could be used to advance $\beta$ cell biology, facilitate drug discovery, and provide a pathway to $\beta$ cell replacement therapy for the treatment of diabetes. In this issue of the JCI, Ravassard and colleagues report that this has finally been achieved successfully with a multistep process that led to the generation of cells, which they termed EndoC- $\beta H 1$ cells, that secreted insulin in response to glucose challenge.
\end{abstract}

The pancreas is a complex organ with endocrine and exocrine compartments. The endocrine compartment consists of $\alpha, \beta$, $\delta$, and pancreatic polypeptide cells, which produce glucagon, insulin, somatostatin, and pancreatic polypeptide, respectively. These cells are organized into islets of Langerhans, which are scattered throughout the exocrine pancreas. Loss of pancreatic $\beta$ cell function as a result of autoimmune-mediated destruction and failure of pancreatic $\beta$ cells to produce enough insulin to meet the body's demands result in type 1 and type 2 diabetes, respectively.

Even though $\beta$ cells are the predominant cell type within islets of Langerhans, they comprise approximately $1 \%-2 \%$ of total pancreatic cells only. Isolating a homogenous population of $\beta$ cells has therefore proven difficult, hampering studies of human pancreatic $\beta$ cell physiology as well as studies of the pathogenesis of diabetes and the development of therapeutics - both pharmacologic and cell based - to treat diabetes. Many questions pertinent to these issues could be addressed

Conflict of interest: The authors have declared that no conflict of interest exists.

Citation for this article: J Clin Invest. 2011; 121(9):3395-3397. doi:10.1172/JCI58899. by studies using a human pancreatic $\beta$ cell line. Despite decades of attempts by many, human pancreatic $\beta$ cell lines that retain the characteristics of primary $\beta$ cells remain unavailable. However, in this issue of the JCI, Ravassard and coworkers report that they have finally succeeded in generating a cell line from human pancreatic $\beta$ cells (which they named EndoC- $\beta$ H1) that maintains many of the characteristics of primary mature $\beta$ cells (1).

\section{Lessons from 30 years of work in rodents}

When developing a strategy to generate a human pancreatic $\beta$ cell line, Ravassard and colleagues clearly took to heart lessons from the development of rodent cell lines. The generation of rodent pancreatic $\beta$ cell lines followed several decades of work in which several steps of the process were developed. In one of the earliest pertinent studies, it was found that an insulin-producing pancreatic tumor, which appeared after irradiation of rats, could be propagated as a transplantable insulinoma (2). After this, a way was found to passage these insulinoma cells in vitro as RIN cells $(3,4)$. These cells exhibited some phenotypic instability, as clones contained variable amounts of insulin and the $\delta$ cell product somatostatin. Nonetheless, some of the subcloned cell lines had a stable enough phenotype to have important research value. The next advance was achieved with cells from the same transplantable insulinoma, with the finding that treatment of the cells with 2-mercaptoethanol, which maintained glutathione levels, resulted in the generation of cells (known as INS1 cells) that had impressively improved insulin content relative to the insulinoma cells and superior ability to secrete insulin following stimulation with glucose, a phenotype resembling primary pancreatic $\beta$ cells (5). Further improvements of INS1 cells in terms of insulin content and secretion were then obtained with clonal selection techniques to obtain a cell line called $823 / 13$ (6). In work going on in parallel, the oncogene simian virus 40 large tumor antigen (SV40LT) was first used to make cells with $\beta$ cell characteristics when HIT cells were generated from infected isolated islets from hamsters (7). Work in mice with the same oncogene then led to the generation of $\beta$ TC cells (8) and MIN6 cells (9), which remain among the most widely used rodent pancreatic $\beta$ cell lines today.

\section{A multistep process starting with human fetal pancreas}

The remarkable achievement of Ravassard and colleagues was accomplished by starting with fetal pancreatic buds (1) (Figure 1). These were transduced with a lentiviral vector expressing SV40LT under the control of the insulin promoter and then transplanted into SCID mice to allow expansion of the transformed $\beta$ cells to proceed over 